\title{
AVALIAÇÃOAGRONÔMICA DE GENÓTIPOS DE BANANEIRAS EM CONDIÇÕES SUBTROPICAIS, VALE DO RIBEIRA, SÃO PAULO - BRASIL ${ }^{1}$

\author{
EDSON SHIGUEAKI NOMURA ${ }^{2}$, ERVAL RAFAEL DAMATTO JUNIOR ${ }^{3}$, \\ EDUARDO JUN FUZITANI ${ }^{2}$, EDSON PERITO AMORIM ${ }^{3}$, SEBASTIÃO DE OLIVEIRA E SILVA ${ }^{3}$
}

RESUMO - Existe grande número de cultivares de bananeira no Brasil, porém quando se consideram aspectos como preferência dos consumidores, produtividade, tolerância às pragas e doenças, porte adequado e resistência à seca e ao frio, restam poucas com potencial agronômico para serem usadas comercialmente. Objetivando avaliar o desenvolvimento vegetativo de genótipos de bananeiras nas condições edafoclimáticas do Vale do Ribeira (Brasil), foram testados os seguintes materiais, separados em dois grupos genômicos: AAAA (Bucaneiro, FHIA 02 e FHIA 17); e AAAB, sendo este subdividido de acordo com a genitora utilizada no melhoramento: Prata (BRS Garantida, FHIA 18, BRS FHIA Maravilha, BRS Platina e PA94-01); Pacovan (BRS Japira, BRS Pacovan Ken, PV79-34, PV94-01 e BRS Vitória); e Yangambi n.2 (BRS Tropical, BRS Princesa e YB42-03). As cultivares Grande Naine (AAA), Pacovan (AAB), Prata-anã (AAB) e Yangambi ou Caipira (AAA) apresentam desenvolvimento e produção semelhantes aos genótipos avaliados, portanto foram utilizadas como padrão comparativo. Durante dois ciclos, foram avaliadas as seguintes características de desenvolvimento: altura, diâmetro do pseudocaule, número de folhas ativas (florescimento e colheita), intervalo entre plantio e florescimento, e entre plantio e colheita (dias). Calcularam-se os intervalos de confiança (média \pm erro-padrão) nos diferentes grupos e tipos de banana. Diante dos resultados obtidos conclui-se que os genótipos do grupo AAAB e genitora 'Pacovan' não são adequados para o cultivo na região devido ao porte alto das plantas, e os genótipos de bananeiras que possuem potencial de cultivo na região do Vale do Ribeira são: grupo AAAA (FHIA 02 e FHIA 17); grupo AAAB: genitora 'Prata' (FHIA 18, BRS Garantida e PA94-01) e genitora 'Yangambi n.2' (BRS Tropical, BRS Princesa e Yangambi).

Termos para indexação: Musa sp., cultivares, melhoramento.

\section{AGRONOMIC EVALUATION OF BANANA PLANTS GENOTYPES IN SUBTROPICAL CONDITIONS, VALE DO RIBEIRA, SÃO PAULO - BRAZIL}

ABSTRACT - There is a large number of banana cultivars in Brazil, but considering consumer preference, productivity, tolerance to pests and diseases, appropriate size and resistance to drought and cold, there are few cultivars with agronomic potential to be used commercially. Aiming to evaluate the vegetative development of banana genotypes at Vale do Ribeira (Brazil) conditions the following materials were tested, separated into two genomic groups: AAAA (Bucaneiro, FHIA 02 and FHIA 17), and AAAB, subdivided according to the cultivar used in the breeding: Prata (BRS Garantida, FHIA 18, BRS FHIA Maravilha, BRS Platina and PA94-01); Pacovan (BRS Japira, BRS Pacovan Ken, PV79-34, PV94-01 and BRS Vitória); and Yangambi n.2 (BRS Tropical, BRS Princesa and YB42-03). The cultivars Grande Naine (AAA), Pacovan (AAB), Prata anã (AAB) and Yangambi (AAA) present development, production and sensory characteristics similar to the evaluated genotypes, so they were used to compare to standards. During two cycles it was evaluated: height, pseudo stem diameter, number of active leaves (on blooming and in the harvest), the interval between planting and blooming and the interval between planting and harvest (days). It was calculated confidence intervals in different groups and types of bananas. According to the obtained data it can be concluded that genotypes from AAAB group with 'Paconvan' genitor cultivar are not suitable for cultivation in the region due to the plants height. The genotypes that have potential to be cultivated in Vale do Ribeira region are: AAAA (FHIA 02 and FHIA 17), AAAB group with 'Prata' genitor cultivar (FHIA 18, BRS Garantida and PA94-01) and with 'Yangambi n.2' genitor cultivar (BRS Tropical, BRS Princesa and Yangambi).

Index terms: Musa spp., cultivars, breeding.

\footnotetext{
1(Trabalho 112-12). Recebido em: 19-03-2012. Aceito para publicação em: 07-01-2013. Apoio: CNPq - Conselho Nacional de Pesquisa. Proc. 68.0009/2005-1

${ }^{2}$ Pesquisadores científicos da Agência Paulista de Tecnologia dos Agronegócios - Pólo Regional Vale do Ribeira. Rod. BR-116, km 460, C. P. 122, CEP 11900-000, Registro, SP. E-mails: edsonnomura@apta.sp.gov.br, erval@apta.sp.gov.br, edufuzitani@apta.sp.gov.br ${ }^{3}$ Pesquisador da Empresa Brasileira de Pesquisa Agropecuária - Mandioca e Fruticultura Tropical. Rua Embrapa s/n ${ }^{\circ}$, Cruz das AlmasBA. edson@cnpmf.embrapa.br; ssilva3000@gmail.com
} 


\section{INTRODUÇÃO}

A bananeira (Musa sp.) é uma das fruteiras mais cultivadas nos países tropicais, e seu fruto, um dos mais consumidos no mundo, podendo ser processada, frita, cozida e consumida in natura, e também pelas suas características de sabor, aroma, higiene e facilidade de consumo in natura (DONATO et al., 2006). No Brasil, é cultivada em todos os Estados da federação, com produção, em 2010, de cerca de 6,96 milhões de toneladas e plantada em aproximadamente $487 \mathrm{mil} \mathrm{ha,} \mathrm{superada} \mathrm{somente} \mathrm{pela} \mathrm{laranja}(18,1$ milhões de toneladas e 775,9 mil ha) (IBGE, 2012).

A principal região produtora de bananas no Estado de São Paulo concentra-se no Vale do Ribeira, com produção, em 2010 , de cerca de 835,3 mil toneladas da fruta (67,8\% do Estado) em cerca de 33,5 mil ha (60,0\% do Estado), segundo dados do IBGE (2012), sendo caracterizado pelo cultivo em propriedades de pequeno porte, importante na geração de emprego e renda, e fixação do homem no campo.

Existe grande número de cultivares de bananeiras cultivadas tradicionalmente no Brasil (Nanica, Nanicão, Grande Naine, Prata-anã, Pacovan, Maçã, Terra, etc.), porém quando se consideram algumas características, como porte da planta, produtividade, tolerância a pragas, doenças, seca e frio, todas apresentam pelo menos uma característica indesejável para exploração comercial. Além das características agronômicas, é necessário selecionar cultivares que atendam à preferência dos consumidores em relação a sabor da banana (SILVA;ALVES, 1999). Assim sendo, na substituição de cultivares tradicionalmente consumidas, é necessário combinar alta produtividade, resistência às pragas e doenças, e que produzam frutos com boas características de pós-colheita e organolépticas.

Uma das estratégias para solucionar a falta de cultivares "adequadas" é a criação de novos genótipos resistentes a doenças e pragas, que apresentem porte baixo, que sejam altamente produtivos e apresentem sabor semelhante às cultivares tradicionalmente aceitas pelos consumidores. Para isso, no Brasil, a EMBRAPA Mandioca e Fruticultura Tropical, Cruz das Almas (BA), utiliza-se do melhoramento genético para a obtenção de híbridos tetraploides superiores a partir do cruzamento das cultivares triploides tradicionais com diploides, que foram avaliados em diferentes ambientes nos Estados pelas instituições de pesquisa (SILVA et al., 2003a). Após a obtenção de novos genótipos, a etapa final do melhoramento constitui na avaliação desses materiais em áreas de produção (SILVA et al., 1998), em diferentes condições edafoclimáticas.
Diante do exposto, este trabalho teve por objetivo avaliar o desenvolvimento vegetativo de 20 genótipos de bananeira nas condições edafoclimáticas da região do Vale do Ribeira, Estado de São Paulo.

\section{MATERIAL E MÉTODOS}

O experimento foi conduzido na fazenda do Polo Regional Vale do Ribeira, da Agência de Pesquisa de Tecnologia dos Agronegócios (APTA), município de Pariquera-Açu-SP. (243' $31^{\prime \prime}$ sul; $47^{\circ} 53^{\prime} 48^{\prime \prime}$ oeste e $25 \mathrm{~m}$ s.n.m). O clima, segundo a classificação de Köppen, é Af: tropical chuvoso, sem estação seca, com a precipitação média do mês mais seco superior a $60 \mathrm{~mm}$. O solo foi classificado por Sakai e Lepsche (1984) como Cambissolo distrófico.

Foram utilizadas mudas micropropagadas em laboratório e devidamente aclimatizadas sob viveiro coberto, com malha preta com $50 \%$ de sombreamento, durante dois meses. Os genótipos (híbridos tetraploides) avaliados foram separados em dois grupos genômicos: AAAA: Bucaneiro (Highgate), FHIA 02 (Williams x SH33-93), FHIA 17 (híbrido Gros Michel); e AAAB, sendo este subdividido de acordo com a genitora utilizada no melhoramento: Prata: FHIA 18, BRS Garantida (ST42-08), BRS FHIA Maravilha (FHIA 01), BRS Platina (PA42-44) e PA94-01; Pacovan: BRS Japira (PV42-142), BRS Pacovan Ken (PV42-68), PV79-34, PV94-01 e BRS Vitória (PV42-81); e Yangambi n.2: BRS Tropical (YB42-21), BRS Princesa (YB42-07) e YB42-03, além das cultivares Grande Naine, Prata-anã, Pacovan e Yangambi ou Caipira, que foram incluídas para servir de comparação, por serem tradicionalmente cultivadas no Brasil (Grande Naine, Prata-anã e Pacovan) ou pela semelhança no desenvolvimento e produção com os genótipos híbridos avaliados (Yangambi ou Caipira).

$\mathrm{O}$ delineamento experimental foi o inteiramente casualisado, sendo cada genótipo plantado em bloco único com 20 plantas, no espaçamento $2,5 \mathrm{x}$ 3,0 m, onde se avaliaram oito plantas úteis, e cada planta constituiu de uma repetição.

Antes do preparo da área, o solo foi analisado nas camadas de 0-20 e 20-40 cm, e apresentava as seguintes características, respectivamente: $\mathrm{pH}$ $\left(\mathrm{CaCl}_{2}\right)=4,3$ e 4,5; matéria orgânica $=26,0$ e $18,0 \mathrm{~g}$ $\mathrm{dm}^{-3} ; \mathrm{P}($ resina $)=11,0$ e $151,0 \mathrm{mg} \mathrm{dm}^{-3} ; \mathrm{K}=1,2$ e 0,7 mmolc dm ${ }^{-3} ; \mathrm{Ca}=13,0$ e 7 mmolc dm $^{-3} ; \mathrm{Mg}=3,0$ e 1,0 mmolc dm ${ }^{-3} ; \mathrm{H}+\mathrm{Al}=52,0$ e $64,0 \mathrm{mmolc} \mathrm{dm}^{-3} ; \mathrm{SB}=$ 17,2 e $8,7 \mathrm{mmolc} \mathrm{dm}^{-3}$; CTC $=69,4$ e 73,1 mmolc $\mathrm{dm}^{-3}$, e $\mathrm{V}=25,0$ e $12,0 \%$.

O solo foi preparado dois meses antes do plantio das bananeiras, com a realização de aração e 
gradagem, seguido da aplicação de fósforo $(110 \mathrm{~kg}$ $\mathrm{ha}^{-1}$ de $\mathrm{P}_{2} 0_{5}$ ) e de calcário dolomítico em área total, em quantidade recomendada, conforme a análise de solo, para elevar a saturação por bases a $60 \%$ e

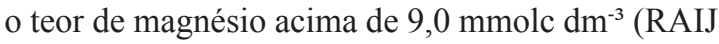
et al., 1997).

Os cálculos das doses de potássio e nitrogênio para o plantio e formação foram realizados de acordo com os resultados da análise de solo e a produtividade esperada de 30-40 tha ${ }^{-1}$, na qual se aplicaram, nas adubações de plantio e formação, as doses de $270 \mathrm{~kg} \mathrm{ha}^{-1}$ de $\mathrm{Ne} 390 \mathrm{~kg} \mathrm{ha}^{-1}$ de $\mathrm{K}_{2} \mathrm{O}$, sendo que os intervalos e a forma de aplicação seguiram as recomendações de Teixeira et al. (1997).

O bananal foi conduzido no sistema família (mãe-filho-neto), por meio de desbastes dos filhos excedentes, deixando-se apenas um seguidor por geração. Não foi realizado o controle químico de pragas e doenças, ao passo que o controle das plantas daninhas foi realizado por meio da aplicação regular de herbicida à base de glufosinato de amônia, mantendo-se com baixo nível de infestação das mesmas.

Durante dois ciclos de produção, foram avaliadas as seguintes características de desenvolvimento: altura da planta: medida do nível do solo até a inserção da última folha aberta, após o florescimento; diâmetro do pseudocaule no florescimento: obtida com o uso de uma fita métrica a $30 \mathrm{~cm}$ acima do nível do solo, após o florescimento; número de folhas ativas no florescimento e na colheita: foram consideradas aquelas que apresentavam área verde acima de 50\%; intervalo entre o plantio e o florescimento, e entre o plantio e a colheita (dias). Para os dados obtidos nestes parâmetros, foram calculados os intervalos de confiança (média \pm erro-padrão), separados em diferentes grupos e tipos de bananas.

\section{RESULTADOS E DISCUSSÃO}

\section{Altura da planta}

A altura da planta é um parâmetro importante do ponto de vista fitotécnico e de melhoramento, principalmente no momento da implantação de uma nova área de plantio, pois interfere no espaçamento a ser utilizado e, consequentemente, na densidade e na produtividade (SANTOS et al., 2006; BELALCÁZAR-CARVAJAL, 1991). Além disso, associa-se o porte elevado das plantas á maior incidência à quebra do pseudocaule ou tombamento de plantas pela ação de ventos fortes e/ou ataque intenso de broca e nematoides (TEIXEIRA, 2001), além de provocar danos aos frutos devido à dificuldade na colheita dos cachos.

Nos genótipos do grupo AAAA, observou- -se diferença na altura de plantas após a emissão da inflorescência, onde o genótipo Grande Naine apresentou menor altura nos dois ciclos de produção ( $1^{\circ}$ ciclo: $246,4 \pm 7,0 \mathrm{~cm} ; 2^{\circ}$ ciclo: $282,4 \pm 10,2 \mathrm{~cm}$ ), seguidos dos genótipos 'FHIA 02', 'Bucaneiro' e 'FHIA 17' (Figura 1A). Houve incremento em altura das plantas entres os ciclos avaliados, pois a estabilidade de altura foi atingida posteriormente, observada normalmente do $1^{\circ}$ para o $2^{\circ}$ ciclo (LIMA et al., 2005; DONATO et al., 2003; SILVA et al., 2003b; SILVA et al., 2002; SOTO-BALLESTERO, 1992; BELALCÁZAR-CARVAJAL, 1991).

As plantas do genótipo Grande Naine apresentaram alturas semelhantes às obtidas por Ramos et al. (2009) e Donato et al. (2006) no $1^{\circ}$ ciclo de produção e superiores às obtidas por Lédo et al. (2008), Oliveira et al. (2008), Oliveira et al. (2007), Pereira et al. (2003) e Silva et al. (2002), nos dois ciclos de produção, e valores inferiores aos obtidos por Leite et al. (2003), no $1^{\circ}$ ciclo de produção. Para o genótipo FHIA 02, os autores Lédo et al. (2008) e Donato et al. (2006) obtiveram resultados inferiores comparados com do presente trabalho. Lédo et al. (2008), Oliveira et al. (2008), Donato et al. (2006) e Lima et al. (2005) obtiveram alturas inferiores ao presente trabalho para o genótipo Bucaneiro.

No grupo AAAB e genitora 'Prata', o genótipo PA94-01 apresentou menor altura no $1^{\circ}$ e $2^{\circ}$ ciclos de produção $(275,9 \pm 8,9 \mathrm{~cm} ; 356,8 \pm 17,7 \mathrm{~cm}$, respectivamente), juntamente com os genótipos BRS Platina (respectivamente, $280,9 \pm 8,8 \mathrm{~cm} ; 355,3 \pm 12,5$ $\mathrm{cm}$ ), FHIA 18 (respectivamente, $277,3 \pm 5,9 \mathrm{~cm}$; $353,8 \pm 30,5 \mathrm{~cm}$ ) e Prata-anã (respectivamente, $266,3 \pm 7,6 \mathrm{~cm} ; 349,4 \pm 11,1 \mathrm{~cm}$ ) (Figura 1B). O menor porte das plantas destes genótipos deve- se à genitora 'Prata-anã', em que são encontrados na literatura valores que variaram entre $208,0-290,3 \mathrm{~cm}$ no $1^{\circ}$ ciclo e $252,0-359,0 \mathrm{~cm}$ no $2^{\circ}$ ciclo de produção (RAMOS et al., 2009; LÉDO et al., 2008; OLIVEIRA et al., 2008; OLIVEIRA et al., 2007; RODRIGUES et al., 2006; DONATO et al., 2006; LEITE et al., 2003; PEREIRA et al., 2003; SILVA et al., 2002), dentro da faixa observada neste trabalho. Plantas do genótipo BRS Garantida apresentaram maior altura, ultrapassando $400 \mathrm{~cm}$ na época da emissão da inflorescência no $2^{\circ}$ ciclo de produção (Figura 1B), resultados esses semelhantes aos obtidos por Lima et al. (2005), Lédo et al. (2008) e Azevedo et al. (2010); assim sendo, esse porte mais elevado das plantas prejudica na indicação desta cultivar.

No grupo AAAB e genitora 'Pacovan', o genótipo BRS Vitória apresentou maior altura de plantas ( $1^{\circ}$ ciclo: $429,9 \pm 7,0 \mathrm{~cm} ; 2^{\circ}$ ciclo: $588,5 \pm 9,7$ $\mathrm{cm})$, diferindo dos demais genótipos nos dois ciclos 
de produção, enquanto o genótipo PV79-34 foi o que apresentou plantas de menor porte nos dois ciclos de produção $\left(1^{\circ}\right.$ ciclo: $332,5 \pm 21,5 \mathrm{~cm} ; 2^{\circ}$ ciclo: $401,7 \pm 18,3 \mathrm{~cm})$, porém ultrapassando $400 \mathrm{~cm}$ no $2^{\circ}$ ciclo de produção (Figura 1C), o que prejudicou os tratos culturais e a colheita dos cachos. Para os genótipos deste grupo e cruzamento, são esperadas plantas altas, uma vez que a genitora de todos os genótipos avaliados é a Pacovan, para a qual se encontram na literatura valores entre $202,3-386,0 \mathrm{~cm}$ no $1^{\circ}$ ciclo e $334,0-576,0 \mathrm{~cm}$ no $2^{\circ}$ ciclo de produção (AZEVEDO et al., 2010; LÉDO et al., 2008; OLIVEIRA et al., 2008; DONATO et al., 2006; LIMA et al., 2005; LEITE et al., 2003; SILVA et al., 2002). Nos híbridos obtidos pela EMBRAPA Mandioca e Fruticultura, as diferenças em altura, para mais ou para menos, estiveram bem próximas das alturas de suas genitoras ('Prata-anã' e 'Pacovan'), o que demonstrou que esta característica é de fundamental importância, especialmente na seleção do genitor masculino de menor porte (LEITE et al., 2003).

No grupo AAAB e genitora 'Yangambi n.2' não se observaram diferenças entre os genótipos no $1^{\circ}$ ciclo de produção (Figura 1D). Devido à utilização da genitora feminina 'Yangambi n. 02', a característica de porte alto foi transmitida aos seus híbridos descendentes ('YB42-03', 'BRS Princesa' e 'BRS Tropical'). No $2^{\circ}$ ciclo de produção, o genótipo BRS Tropical apresentou menor altura, porém ultrapassando $400 \mathrm{~cm}$ de estatura (Figura 1D), o que também prejudicou os tratos culturais e a colheita dos cachos. Para este último genótipo, Lima et al. (2005), Lédo et al. (2008) e Ramos et al. (2009) relataram altura de planta, no $1^{\circ}$ ciclo de produção, inferior ao presente trabalho.

\section{Diâmetro do pseudocaule}

O diâmetro do pseudocaule é importante no melhoramento genético da bananeira, pois está relacionado ao vigor, e reflete a capacidade de a planta sustentar a massa do cacho. Os genótipos que apresentam maior diâmetro do pseudocaule são mais resistentes à quebra do pseudocaule e/ou tombamento das plantas (SILVA et al., 1999), sendo que, no grupo AAAA, no $1^{\circ}$ ciclo de produção, a 'FHIA $17^{\prime}$ ' apresentou maior o diâmetro do pseudocaule, com valor de $29,8 \pm 0,5 \mathrm{~cm}$ (Figura 1E), maior que o genótipo Grande Naine, cultivado nas tradicionais regiões produtoras de banana. No $2^{\circ}$ ciclo de produção, além da 'FHIA 17', o genótipo Bucaneiro apresentou maior desenvolvimento em diâmetro do pseudocaule (33,3 $\pm 0,7 \mathrm{~cm} ; 34,0 \pm 1,1 \mathrm{~cm}$, respectivamente), valores estes maiores que os relatados por Lédo et al. (2008), Oliveira et al. (2008), Donato et al. (2006) e
Lima et al. (2005) para 'Bucaneiro'.

No grupo AAAB e genitora 'Prata', os maiores diâmetros de pseudocaule, no $1^{\circ}$ ciclo de produção, foram encontrados nos genótipos BRS FHIA Maravilha, PA94-01, Prata-anã, BRS Platina e BRS Garantida (Figura 1F). A semelhança entre os genótipos PA94-01 e BRS Platina foi devido à herança adquirida da genitora em comum ('Prata-anã'), corroborando os resultados obtidos por Oliveira et al. (2008), que também não observaram diferenças entre a 'Prata-anã' e a 'BRS Platina' no $1^{\circ}$ e $2^{\circ}$ ciclos de produção. No $2^{\circ}$ ciclo de produção, o genótipo BRS FHIA Maravilha obteve maior desenvolvimento em diâmetro (33,3 $\pm 1,5 \mathrm{~cm})$, quando comparado com os demais genótipos (Figura 1F).

No grupo AAAB e genitora 'Pacovan', foram observadas diferenças no $1^{\circ}$ ciclo de produção, com maior desenvolvimento de diâmetro dos pseudocaules nos genótipos PV79-34, BRS Pacovan Ken, BRS Vitória e BRS Japira (Figura 1G). Oliveira et al. (2008) relataram valores menores de diâmetro de pseudocaule para os genótipos BRS Japira e BRS Pacovan Ken aos obtidos no presente trabalho. No $2^{\circ}$ ciclo de produção, observou-se maior desenvolvimento nos genótipos BRS Vitória $(33,5 \pm 1,6 \mathrm{~cm}) \mathrm{e}$ PV79-34 (30,2 $\pm 1,7 \mathrm{~cm})$ quando comparado com os demais genótipos deste grupo e cruzamento.

O genótipo BRS Tropical mostrou-se superior, comparado aos demais genótipos do grupo AAAB e genitora 'Yangambi n.2', quanto ao diâmetro de pseudocaule no $1^{\circ}$ e $2^{\circ}$ ciclos de produção $(27,1 \pm 0,9 \mathrm{~cm} ; 30,6 \pm 1,2 \mathrm{~cm}$, respectivamente), juntamente com o YB42-03 no $2^{\circ}$ ciclo $(30,2 \pm 0,8$ $\mathrm{cm})($ Figura $1 \mathrm{H})$. Os resultados obtidos por Ramos et al. (2009), Lédo et al. (2008) e Lima et al. (2005) corroboram os resultados determinados neste trabalho para o genótipo BRS Tropical, com variação de valores entre 23,0-27,5 cm de diâmetro. Os genótipos BRS Tropical, BRS Princesa e YB42-03 apresentam diâmetros de pseudocaule próximos devido à similaridade do cruzamento (Yangambi n.2 x M53).

Número de folhas ativas no florescimento e na colheita

A quantidade de folhas na emissão da inflorescência é um parâmetro importante para o desenvolvimento da planta e do cacho, principalmente nas avaliações de resistência ou tolerância às doenças foliares, como o fungo Mycosphaerella fijiensis Morelet (Sigatoka-negra), que diminui a área fotossinteticamente ativa $\mathrm{e}$, consequentemente, reduz a produção. Tão importante quanto um número adequado de folhas no momento da floração, é necessário que a planta consiga manter as folhas 
durante o período de enchimento dos frutos, já que não há emissão foliar após a floração (RODRIGUES et al., 2006).

Outra variável importante no que diz respeito à resistência às doenças foliares é o número de folhas ativas na colheita, pois correlaciona- se diretamente ao enchimento dos frutos (tamanho) (LIMA et al., 2005). De acordo com Belalcázar-Carvajal (1991) e Soto-Ballestero (1992), nas cultivares do grupo Nanica, é necessária a manutenção de, no mínino, oito folhas ativas para o desenvolvimento normal dos frutos até a colheita. Na prática, os bananicultores mantêm, no mínimo, número igual de folhas ativas ao de pencas até a colheita (TEIXEIRA et al., 2001). Diante disso, no florescimento, no grupo AAAA, observou-se maior quantidade de folhas no genótipo FHIA 02, nos dois ciclos de produção $\left(1^{\circ}\right.$ ciclo: $12,1 \pm 0,5$ folhas; $2^{\circ}$ ciclo: $11,6 \pm 1,2$ folhas), quantidade de folhas próximas ao encontrado por Donato et al. (2006) e Oliveira et al. (2008) e inferiores ao encontrado por Lédo et al. (2008) no $1^{\circ}$ ciclo.

$\mathrm{Na}$ colheita dos cachos, os genótipos FHIA 02 e FHIA 17 apresentavam, respectivamente, $3,9 \pm 0,9$ e $4,1 \pm 0,5$ folhas ativas no $1^{\circ}$ ciclo e $7,0 \pm 0,6$ e $4,5 \pm 0,9$ folhas ativas no $2^{\circ}$ ciclo. Lédo et al. (2008) e Donato et al. (2006) encontraram quantidades superiores de folhas ativas, na colheita, a este estudo na 'FHIA 02', isto devido ao cultivo deste genótipo na Bahia e Sergipe, Estados que apresentam somente o fungo da Sigatoka-amarela (Mycosphaerella musicola Colla). De acordo com a FHIA (2010), o genótipo desenvolvido por esta instituição apresenta tolerância ao fungo da Sigatoka-negra, o que proporciona maior número de folhas ativas na planta. Nos demais genótipos (Bucaneiro e Grande Naine), o fungo causador da Sigatoka-negra inutilizou totalmente as folhas, antecipando a colheita dos cachos, fato também observado por Oliveira et al. (2008) em Rio Branco-AC.

No grupo AAAB e genitora 'Prata', os genótipos que apresentaram maior número de folhas ativas no florescimento foram: 'FHIA $18^{\prime}$ ' $\left(1^{\circ}\right.$ ciclo: $13,9 \pm 1,1 ; 2^{\circ}$ ciclo: $\left.11,5 \pm 1,1\right)$, 'BRS Garantida' $\left(1^{\circ}\right.$ ciclo: $13,0 \pm 1,0$; $2^{\circ}$ ciclo: $\left.11,3 \pm 0,7\right)$ e 'PA94-01' ( $1^{\circ}$ ciclo: $12,9 \pm 0,9 ; 2^{\circ}$ ciclo: $\left.11,1 \pm 1,7\right)$ (Tabela 1 ). Azevedo et al. (2010), Lédo et al. (2008) e Lima et al. (2005) relataram quantidades de folhas ativas no florescimento nos genótipos FHIA 18 e BRS Garantida próximas às obtidas neste trabalho. Quando se compararam os ciclos de produção, constatou-se redução significativa do número de folhas ativas na 'FHIA 18'. Os genótipos FHIA 18, BRS Garantida e PA94-01 também foram aqueles que mantiveram maior número de folhas ativas na colheita dos cachos, sendo que, nos demais genótipos, a colheita foi antecipada devido à ausência de folhas ativas para o enchimento dos frutos. Na literatura, é encontrado número de folhas na colheita para o genótipo BRS Garantida entre 5,7-8,2 no $1^{\circ}$ ciclo e entre 4,9-8,0 no $2^{\circ}$ ciclo (AZEVEDO et al., 2010; LÉDO et al., 2008; LIMA et al., 2005). O genótipo PA94-01, apesar de ser um descendente da 'Prata-anã, mas cruzado com SH 3263, apresentou resistência ao fungo causador da Sigatoka-negra, pois manteve até à colheita número de folhas suficiente para o enchimento dos frutos ( $1^{\circ}$ ciclo: $4,5 \pm 0,7$ folhas; $2^{\circ}$ ciclo: $4,5 \pm 0,4$ folhas).

Observou-se, no grupo AAAB e genitora ' $\mathrm{Pa}$ covan', que os genótipos BRS Japira, BRS Pacovan Ken, PV94-01 e BRS Vitória apresentaram maior número de folhas ativas nos dois ciclos de produção, quando avaliados no florescimento, porém ocorreu redução significativa entre os ciclos para os genótipos PV94-01 e Vitória (Tabela 1). Esses mesmos genótipos também apresentaram maiores quantidades de folhas ativas na colheita dos cachos; no entanto, o genótipo BRS Vitória apresentou redução significativa entre os dois ciclos de produção. Azevedo et al. (2010) e Donato et al. (2006) relataram número de folhas ativas no florescimento e na colheita dos genótipos BRS Pacovan Ken e BRS Japira dentro do intervalo de confiança deste trabalho, enquanto Oliveira et al. (2008) relataram quantidades menores do que as encontradas neste trabalho. Apesar de os genótipos híbridos deste cruzamento apresentarem a mesma genitora ('Pacovan'), observou-se que aqueles que apresentaram maior número de folha adquiriram características positivas do genitor masculino (M53), principalmente a resistência ao fungo causador da Sigatoka-amarela e da negra.

E no grupo AAAB e genitora 'Yangambi n.2', observou- se que, no $1^{\circ}$ ciclo de produção, o genótipo BRS Princesa apresentou maior número de folhas ativas $(16,1 \pm 1,8)$ no florescimento (Tabela 1), o que corrobora os resultados obtidos por Lédo et al. (2008), em Propriá-SE. No $2^{\circ}$ ciclo de produção, não houve diferença entre os genótipos e entre os ciclos de produção. No entanto, na ocasião da colheita dos cachos, os genótipos Yangambi, BRS Tropical e BRS Princesa apresentaram maior número de folhas ativas, demonstrando que estes apresentam alta resistência ao fungo causador da Sigatoka-negra, mantendo as folhas por um período longo, sem afetar a produção. Nestes genótipos, Lédo et al. (2008) encontraram número superior de folhas ativas na ocasião da colheita ao obtido neste trabalho, devido à ocorrência de somente o fungo causador da Sigatoka-amarela no Estado em que foi realizado este trabalho. 
Ciclo: intervalos entre o plantio e o florescimento e entre o plantio e a colheita

A duração do ciclo vegetativo é uma variável importante no melhoramento genético de bananeira, pois reflete a precocidade do genótipo, especialmente sob o ponto de vista econômico, pois resulta na obtenção de ciclos sucessivos de produção em menor espaço de tempo, aumentando a produção e a produtividade (SILVA et al., 2000). Aliado a isso, o menor tempo de permanência da planta no campo reduz o tempo de exposição dos frutos aos agentes causadores de danos e, consequentemente, menor uso de defensivos agrícolas (RODRIGUES et al., 2006; DAMATTO JUNIOR, 2005).

A redução do número de dias necessária à emissão do cacho é desejada, pois representa a antecipação do retorno do investimento aplicado na lavoura (SANTOS et al., 2006). Sendo assim, observou-se que o genótipo FHIA 02 do grupo AAAA apresentou menor período para o florescimento nos dois ciclos de produção (Tabela 2), e quando cultivado em Propriá-SE (LÉDO et al., 2008), e em Guanambi-BA, Donato et al., (2006) relataram ser ainda mais precoce, pois essas duas regiões apresentam condições climáticas mais adequadas para o desenvolvimento das bananeiras. Já o genótipo FHIA 17 apresentou maior período entre o plantio e o florescimento $\left(1^{\circ}\right.$ ciclo: $360 \pm 11$ dias; $2^{\circ}$ ciclo: $778,1 \pm 43,9$ dias), e o plantio e a colheita ( $1^{\circ}$ ciclo: $536,4 \pm 12,4$ dias; $2^{\circ}$ ciclo: 913,8 $\pm 36,7$ dias), e que, consequentemente, promove redução da produtividade ha-1 $\mathrm{ano}^{-1}$.

Constatou-se, no grupo AAAB e genitora 'Prata', que o genótipo PA94-01 apresentou maior intervalo entre o plantio e o florescimento, e o plantio e a colheita, no $1^{\circ}$ ciclo de produção (Tabela 2). A colheita dos cachos nos genótipos BRS FHIA Maravilha, BRS Platina e Prata-anã foi antecipada devido à ausência de folhas ativas na ocasião da colheita dos cachos, pela infecção do fungo causador da Sigatoka-negra, reduzindo o intervalo entre o florescimento e a colheita. O genótipo Prata-anã apresentou intervalo entre o plantio e o florescimento, entre 207,8-287,3 dias no $1^{\circ}$ ciclo e $362,5-576,1$ dias no $2^{\circ}$ ciclo (LÉDO et al., 2008; DONATO et al., 2006; OLIVEIRA et al., 2007), e o intervalo entre o plantio e a colheita variou entre 360,5-466,9 dias no $1^{\circ}$ ciclo e 501,0-704,7 dias no $2^{\circ}$ ciclo (LÉDO et al., 2008; OLIVEIRA et al., 2007; DONATO et al., 2006; DONATO et al., 2003; LEITE et al., 2003; SILVA et al.; 2002), abaixo das faixas encontradas neste trabalho; porém, estes autores realizaram seus estudos em locais com condições climáticas mais adequadas para o desenvolvimento das plantas (Bahia, Minas Gerais e Sergipe), além da ausência do fungo causador da Sigatoka-negra nestes Estados. E, ao se comparar estes resultados com o genótipo PA94-01, observou- se que ficaram bem próximos, devido à utilização da 'Prata-anã' como genitora.

Observou-se que a variação nos resultados referentes ao ciclo da planta depende das condições edafoclimáticas onde as bananeiras são cultivadas e, segundo Gomes (1980), altas altitudes e baixas temperaturas exercem influência considerável sobre o fenótipo das plantas, aumentando o ciclo da planta. Além do solo e clima, os tratos culturais, como nível de adubação, os tratamentos fitossanitários utilizados e diferenças clonais também podem interferir nas características avaliadas (SIQUEIRA, 1984). Além disso, o ciclo é uma característica que está estreitamente relacionada à época do desbaste, sendo variável de acordo com a cultivar e o local de cultivo, porém nem sempre é realizado no momento adequado por falta de conhecimento destes novos genótipos (SILVA et al., 2002).

Não se observaram diferenças entre os genótipos do grupo AAAB e genitora 'Pacovan' para $o$ intervalo entre plantio e florescimento, e plantio e colheita nos dois ciclos de produção (Tabela 2). De acordo com Azevedo et al. (2010), Donato et al. (2006) e Lima et al. (2005), a 'Pacovan' apresentou intervalos entre o plantio e o florescimento entre $224,9-258,2$ dias no $1^{\circ}$ ciclo e $360,0-546,3$ dias no $2^{\circ}$ ciclo, enquanto o intervalo entre o plantio e a colheita variou entre $375,1-475,1$ dias no $1^{\circ}$ ciclo e 522,1-690,0 dias no $2^{\circ}$ ciclo (AZEVEDO et al., 2010; LÉDO et al., 2008; DONATO et al., 2006; LIMA et al., 2005; LEITE et al., 2003; SILVA et al., 2002), inferior aos resultados obtidos em todos os genótipos híbridos de 'Pacovan' estudados neste trabalho, corroborando os resultados encontrados por Oliveira et al. (2007), que apontam as cultivares BRS Japira e BRS Pacovan Ken como mais tardias que a 'Pacovan'.

No grupo AAAB e genitora 'Yangambi n.2', o genótipo YB42-03 apresentou menor intervalo entre plantio e colheita, nos dois ciclos de produção, porém não diferiu quando comparado com o genótipo BRS Princesa no $1^{\circ}$ ciclo e com os genótipos BRS Princesa e Yangambi no $2^{\circ}$ ciclo de produção (Tabela 2). Estes novos genótipos (YB42-03 e BRS Princesa) apresentaram características semelhantes às de sua genitora, em que em geral o intervalo entre o plantio e a colheita variou no $1^{\circ}$ ciclo entre 382,0-480,0 dias e no $2^{\circ}$ ciclo entre 545,0-640,2 dias (LÉDO et al., 2008; RODRIGUES et al., 2006; LIMA et al., 2005; DONATO et al., 2003; LEITE et al., 2003; SILVA et al., 2002), mais precoces do que relatado neste trabalho. 

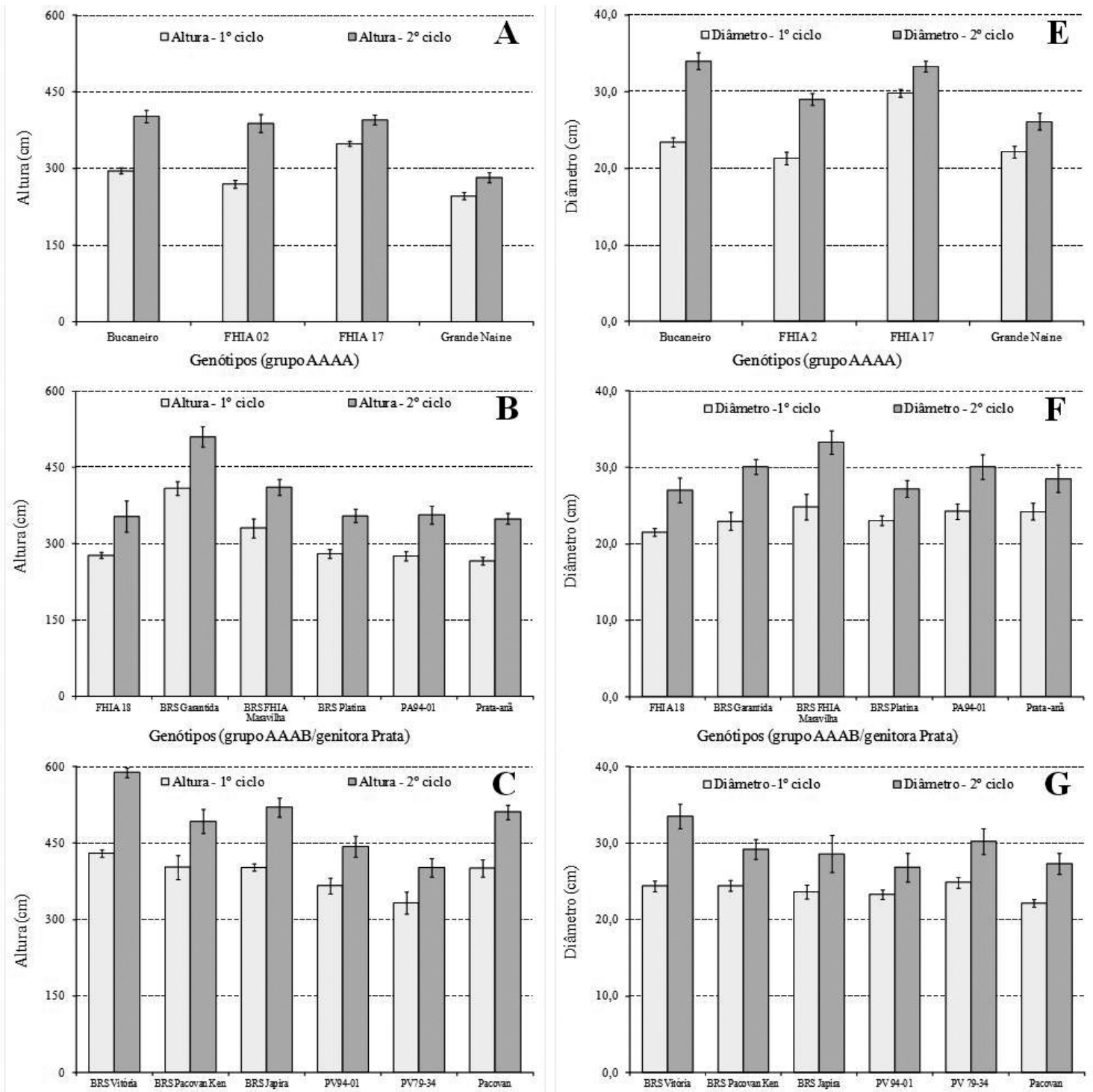

Genótioos (grupo AAAB/genitora Pacovan)

Genótipos (grupo $\mathrm{AAAB} /$ genitora Pacovan)
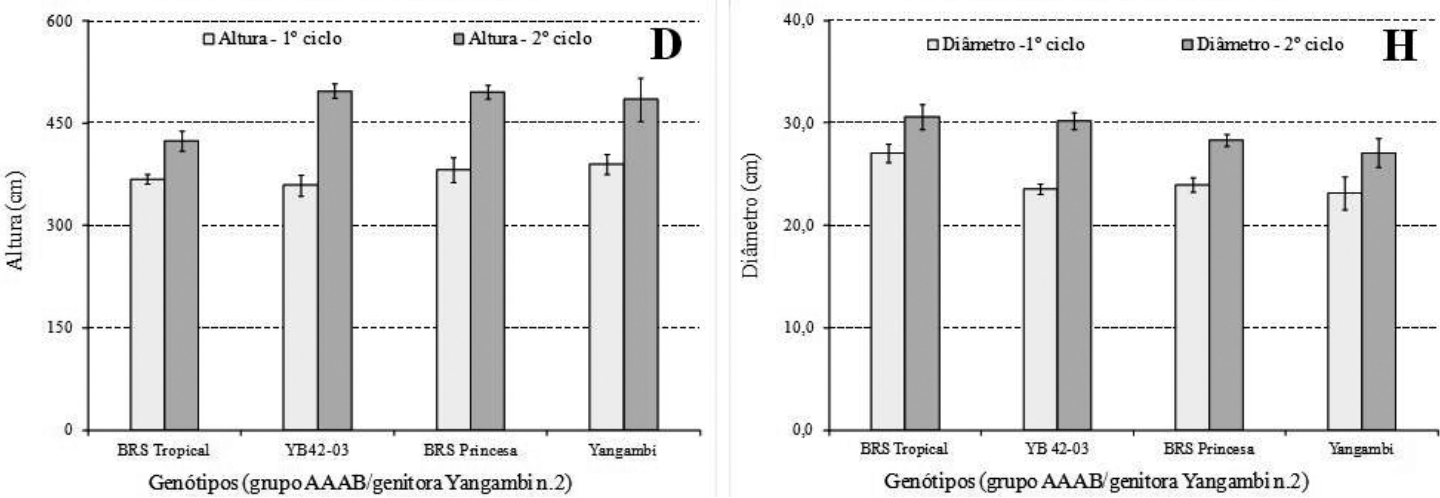

FIGURA 1- Intervalo de confiança da altura (A-D) e diâmetro do pseudocaule (E-H) das plantas no florescimento, de dois ciclos de produção, em diferentes genótipos, separados em grupo e genitora utilizada no melhoramento, Pariquera-Açu-SP, 2010. Média \pm erro-padrão $(n=8)$. FHIA: Fundación Hondureña de Investición Agrícola. 
TABELA 1- Intervalo de confiança do número de folhas ativas no florescimento (NFF) e na colheita (NFC) de diferentes genótipos de bananeiras, separados em grupos, e genitora utilizada no melhoramento, em dois ciclos de produção (2009-2010), Pariquera-Açu, SP, 2011.

\begin{tabular}{|c|c|c|c|c|}
\hline \multirow{2}{*}{ Grupo AAAA } & \multicolumn{2}{|c|}{ NFF } & \multicolumn{2}{|c|}{ NFC } \\
\hline & $1^{\circ}$ ciclo & $2^{\circ}$ ciclo & $1^{\mathrm{o}}$ ciclo & $2^{\circ}$ ciclo \\
\hline Bucaneiro & $9,5 \pm 1,2$ & $9,3 \pm 0,7$ & 0,0 & 0,0 \\
\hline${ }^{1}$ FHIA 02 & $12,1 \pm 0,5$ & $11,6 \pm 1,2$ & $3,9 \pm 0,9$ & $7,0 \pm 0,6$ \\
\hline${ }^{1}$ FHIA 17 & $8,4 \pm 0,4$ & $9,0 \pm 1,0$ & $4,1 \pm 0,5$ & $4,8 \pm 0,6$ \\
\hline Grande Naine & $7,5 \pm 0,6$ & $9,4 \pm 0,9$ & 0,0 & 0,0 \\
\hline \multirow{2}{*}{$\begin{array}{l}\text { Grupo AAAB } \\
\text { genitora Prata }\end{array}$} & \multicolumn{2}{|c|}{ NFF } & \multicolumn{2}{|c|}{ NFC } \\
\hline & $1^{\circ}$ ciclo & $2^{\circ}$ ciclo & $1^{\circ}$ ciclo & $2^{\circ}$ ciclo \\
\hline BRS Garantida & $13,0 \pm 1,0$ & $11,3 \pm 0,7$ & $5,8 \pm 0,8$ & $4,3 \pm 0,7$ \\
\hline${ }^{1}$ FHIA 18 & $13,9 \pm 1,1$ & $11,5 \pm 1,1$ & $4,6 \pm 0,6$ & $6,1 \pm 0,5$ \\
\hline BRS FHIA Maravilha & $8,5 \pm 0,6$ & $9,0 \pm 0,4$ & 0,0 & 0,0 \\
\hline BRS Platina & $9,4 \pm 0,7$ & $6,5 \pm 0,6$ & 0,0 & 0,0 \\
\hline PA94-01 & $12,9 \pm 0,9$ & $11,1 \pm 1,7$ & $4,5 \pm 0,7$ & $4,5 \pm 0,4$ \\
\hline Prata Anã & $9,4 \pm 0,7$ & $9,1 \pm 0,8$ & 0,0 & 0,0 \\
\hline \multirow{2}{*}{$\begin{array}{c}\text { Grupo AAAB } \\
\text { genitora Pacovan }\end{array}$} & \multicolumn{2}{|c|}{ NFF } & \multicolumn{2}{|c|}{ NFC } \\
\hline & $1^{\circ}$ ciclo & $2^{\circ}$ ciclo & $1^{\mathrm{o}}$ ciclo & $2^{\circ}$ ciclo \\
\hline BRS Japira & $13,6 \pm 1,0$ & $13,3 \pm 1,2$ & $7,4 \pm 0,7$ & $6,8 \pm 0,8$ \\
\hline Pacovan & $10,0 \pm 0,9$ & $7,8 \pm 0,9$ & 0,0 & 0,0 \\
\hline BRS Pacovan Ken & $15,3 \pm 1,3$ & $13,0 \pm 1,1$ & $7,0 \pm 0,8$ & $6,0 \pm 0,7$ \\
\hline PV79-34 & $8,0 \pm 1,0$ & $8,3 \pm 0,5$ & 0,0 & 0,0 \\
\hline PV94-01 & $15,5 \pm 1,6$ & $11,3 \pm 1,7$ & $6,9 \pm 0,8$ & $6,6 \pm 0,6$ \\
\hline BRS Vitória & $15,6 \pm 0,7$ & $12,8 \pm 1,4$ & $6,8 \pm 0,8$ & $4,5 \pm 0,4$ \\
\hline \multirow{2}{*}{$\begin{array}{c}\text { Grupo AAAB } \\
\text { genitora Yangambi n.2 }\end{array}$} & \multicolumn{2}{|c|}{ NFF } & \multicolumn{2}{|c|}{ NFC } \\
\hline & $1^{\circ}$ ciclo & $2^{\circ}$ ciclo & $1^{\mathrm{o}}$ ciclo & $2^{\circ}$ ciclo \\
\hline Yangambi & $11,4 \pm 1,7$ & $12,8 \pm 1,2$ & $6,1 \pm 0,7$ & $7,3 \pm 0,7$ \\
\hline BRS Tropical & $11,8 \pm 1,1$ & $10,7 \pm 1,1$ & $5,3 \pm 0,8$ & $3,6 \pm 0,8$ \\
\hline YB42-03 & $9,4 \pm 1,5$ & $10,6 \pm 1,1$ & 0,0 & $1,4 \pm 0,7$ \\
\hline BRS Princesa & $16,1 \pm 1,8$ & $11,5 \pm 0,7$ & $6,1 \pm 0,8$ & $6,1 \pm 0,9$ \\
\hline
\end{tabular}

Intervalo de confiança= Médias \pm erro-padrão $(\mathrm{n}=8) ;{ }^{1}$ Fundación Hondureña de Investición Agrícola. 
TABELA 2- Intervalo de confiança do intervalo entre o plantio e o florescimento (IPF), e intervalo entre o plantio e a colheita (IPC), de diferentes genótipos de bananeiras, separados em grupos, e genitora utilizada no melhoramento, em dois ciclos de produção (2009-2010), Pariquera-Açu, SP, 2011.

\begin{tabular}{|c|c|c|c|c|}
\hline \multirow{2}{*}{ Grupo AAAA } & \multicolumn{2}{|c|}{ IPF (dias) } & \multicolumn{2}{|c|}{ IPC (dias) } \\
\hline & $1^{\circ}$ ciclo & $2^{\circ}$ ciclo & $1^{\circ}$ ciclo & $2^{\circ}$ ciclo \\
\hline Bucaneiro & $299,0 \pm 6,1$ & $633,1 \pm 11,7$ & $434,3 \pm 15,4$ & $747,4 \pm 10,9$ \\
\hline${ }^{1}$ FHIA 02 & $277,4 \pm 11,4$ & $589,6 \pm 31,4$ & $446,0 \pm 19,7$ & $691,3 \pm 35,8$ \\
\hline${ }^{1}$ FHIA 17 & $359,8 \pm 11,0$ & $778,1 \pm 43,9$ & $536,4 \pm 12,4$ & $913,8 \pm 36,7$ \\
\hline Grande Naine & $293,8 \pm 16,6$ & $643,4 \pm 20,2$ & $443,8 \pm 15,4$ & $752,6 \pm 34,0$ \\
\hline \multirow{2}{*}{$\begin{array}{l}\text { Grupo AAAB } \\
\text { genitora Prata }\end{array}$} & \multicolumn{2}{|c|}{ IPF (dias) } & \multicolumn{2}{|c|}{ IPC (dias) } \\
\hline & $1^{\circ}$ ciclo & $2^{\circ}$ ciclo & $1^{\circ}$ ciclo & $2^{\circ}$ ciclo \\
\hline BRS Garantida & $297,4 \pm 13,9$ & $650,8 \pm 60,8$ & $453,6 \pm 29,8$ & $852,0 \pm 74,2$ \\
\hline${ }^{1}$ FHIA 18 & $282,5 \pm 8,8$ & $625,1 \pm 41,2$ & $443,1 \pm 12,8$ & $749,1 \pm 49,4$ \\
\hline BRS FHIA Maravilha & $301,5 \pm 8,0$ & $661,6 \pm 22,1$ & $429,5 \pm 13,8$ & $793,6 \pm 34,3$ \\
\hline BRS Platina & $279,4 \pm 8,0$ & $596,8 \pm 16,2$ & $422,3 \pm 3,3$ & $670,0 \pm 19,7$ \\
\hline PA94-01 & $344,1 \pm 7,8$ & $685,0 \pm 27,3$ & $549,5 \pm 6,6$ & $838,9 \pm 27,9$ \\
\hline Prata Anã & $283,4 \pm 4,2$ & $620,0 \pm 19,0$ & $422,8 \pm 3,2$ & $733,5 \pm 30,2$ \\
\hline \multirow{2}{*}{$\begin{array}{c}\text { Grupo AAAB } \\
\text { genitora Pacovan }\end{array}$} & \multicolumn{2}{|c|}{ IPF (dias) } & \multicolumn{2}{|c|}{ IPC (dias) } \\
\hline & $1^{\circ}$ ciclo & $2^{\circ}$ ciclo & $1^{\circ}$ ciclo & $2^{\circ}$ ciclo \\
\hline BRS Japira & $273,4 \pm 4,4$ & $580,8 \pm 25,2$ & $460,3 \pm 5,0$ & $720,9 \pm 28,3$ \\
\hline Pacovan & $275,5 \pm 12,4$ & $571,6 \pm 19,6$ & $424,8 \pm 10,5$ & $690,8 \pm 5,8$ \\
\hline BRS Pacovan Ken & $308,5 \pm 23,0$ & $619,9 \pm 45,9$ & $504,1 \pm 27,6$ & $754,3 \pm 58,3$ \\
\hline PV79-34 & $320,6 \pm 17,5$ & $610,8 \pm 21,3$ & $466,8 \pm 12,8$ & $757,0 \pm 34,1$ \\
\hline PV94-01 & $275,4 \pm 5,7$ & $591,0 \pm 41,6$ & $439,0 \pm 15,9$ & $718,8 \pm 45,1$ \\
\hline BRS Vitória & $288,1 \pm 5,2$ & $639,6 \pm 17,8$ & $469,5 \pm 21,1$ & $809,3 \pm 15,5$ \\
\hline \multirow{2}{*}{$\begin{array}{c}\text { Grupo AAAB } \\
\text { genitora Yangambi n.2 }\end{array}$} & \multicolumn{2}{|c|}{ IPF (dias) } & \multicolumn{2}{|c|}{ IPC (dias) } \\
\hline & $1^{\circ}$ ciclo & $2^{\circ}$ ciclo & $1^{\circ}$ ciclo & $2^{\circ}$ ciclo \\
\hline Yangambi & $415,6 \pm 41,3$ & $639,9 \pm 12,1$ & $544,6 \pm 21,0$ & $750,8 \pm 23,0$ \\
\hline BRS Tropical & $347,9 \pm 12,8$ & $678,6 \pm 32,4$ & $503,4 \pm 21,4$ & $802,7 \pm 33,7$ \\
\hline YB42-03 & $288,5 \pm 9,5$ & $611,9 \pm 20,5$ & $439,0 \pm 15,9$ & $720,1 \pm 23,6$ \\
\hline BRS Princesa & $299,4 \pm 19,1$ & $635,4 \pm 14,6$ & $453,4 \pm 19,2$ & $747,1 \pm 27,9$ \\
\hline
\end{tabular}

Intervalo de confiança $=$ Médias \pm erro-padrão $(n=8) ;{ }^{1}$ Fundación Hondureña de Investición Agrícola. 


\section{CONCLUSÕES}

1- Os genótipos do grupo genômico AAAB, provenientes da genitora 'Pacovan', não são adequados para o cultivo na região devido ao porte alto das plantas.

2- Os genótipos FHIA 02 e FHIA 17 do grupo genômico AAAA, e os genótipos FHIA 18 e PA94-01 do grupo genômico AAAB, provenientes da genitora 'Prata', apresentam altura, diâmetro do pseudocaule e número de folhas no florescimento e na colheita adequados.

3- Os genótipos FHIA 17 e PA94-01 apresentam ciclo de produção tardia, o que resulta em menor produtividade por hectare por ano.

4- No grupo genômico $\mathrm{AAAB}$ e genitora 'Yangambi n.2', os genótipos Yangambi, BRS Tropical e BRS Princesa apresentam diâmetro do pseudocaule e número de folhas no florescimento e na colheita adequados, porém apresentam plantas muito altas que podem prejudicar no momento da colheita dos cachos.

\section{REFERÊNCIAS}

AZEVEDO, V.F.; DONATO, S.L.R.; ARANTES, A.M.; MAIA, V.M.; SILVA, S.O. Avaliação de bananeiras tipo Prata, de porte alto, no semiárido. Ciência e Agrotecnologia, Lavras, v. 34, n.6, p.13721380, 2010.

BELALCÁZAR-CARVAJAL, S.L. El cultivo del plátano en el trópico. Cali: Feriva, 1991.376p.

DAMATTO JÚNIOR, E.R.; CAMPOS, A.J.; MANOEL, L.; MOREIRA, G.C.; LEONEL, S.; EVANGELISTA, R.M. Produção e caracterização de frutos de bananeira 'Prata-anã' e 'Prata-Zulu'. Revista Brasileira de Fruticultura, Jaboticabal, v. 27, n. 3, p. 440-443, 2005.

DONATO, S.L.R.; SILVA, S.O.; LUCCA FILHO, O.A.; LIMA, M.B.; DOMINGUES, H.; ALVES, J.S. Comportamento de variedades e híbridos de bananeira (Musa spp.), em dois ciclos de produção, no sudoeste da Bahia. Revista Brasileira de Fruticultura, Jaboticabal, v. 28 n. 1, p. 139-144, 2006.

DONATO, S. L. R.; SILVA, S.O.; PASSOS, A.R.; LIMA NETO, F.P.; LIMA, M.B. Avaliação de variedades e híbridos de bananeira sob irrigação. Revista Brasileira de Fruticultura, Jaboticabal, v. 25, n. 2, p. 348-351, 2003.
FHIA - Fundación Hondureña de Investigación Agrícola. Banano FHIA-17. Disponível em: $<$ www.fhia. org.hn>. Acesso em: 10 abr. 2010.

GOMES, W.R. Exigências climáticas da cultura da bananeira. Informe Agropecuário, Belo Horizonte, v. 6, n. 63 , p. $14-15,1980$.

IBGE - Instituto Brasileiro de Geografia e Estatística. Disponível em: <http://www.sidra.ibge.gov.br> Acesso em: 20 ago. 2012.

LÉDO, A.S.; SILVA JÚNIOR, J.F.; LÉDO, C.A.S.; SILVA, S.O. Avaliação de genótipos de bananeira na região do Baixo São Francisco, Sergipe. Revista Brasileira de Fruticultura, Jaboticabal, v. 30, n. 3, p. 691-695, 2008.

LEITE, J.B.V.; SILVA, S.O.; ALVES, E.J.; LINS, R.D.; JESUS, O.N. Caracteres da planta e do cacho de genótipos de bananeira, em quatro ciclos de produção, em Belmonte, Bahia. Revista Brasileira de Fruticultura, Jaboticabal, v. 25, n. 3, p. 443-447, 2003.

LIMA, M.B.; SILVA, S.O.; JESUS, O.N.; OLIVEIRA, W.SJ.; GARRIDO, M.S.; AZEVEDO, R.L. Avaliação de cultivares e híbridos de bananeira no Recôncavo Baiano. Ciência e Agrotecnologia, Lavras, v. 29, n. 3, p. 515-520, 2005.

OLIVEIRA, C.A.P.; PEIXOTO, C.P.; SILVA, S.O.; LÉDO, C.A.S.; SALOMÃO, L.C.C. Genótipos de bananeira em três ciclos na Zona da Mata Mineira. Pesquisa Agropecuária Brasileira, Brasília, v.42, n.2, p.173-181, 2007.

OLIVEIRA, T.K.; LESSA, L.S.; SILVA, S.O.; OLIVEIRA, J.P. Características agronômicas de genótipos de bananeira em três ciclos de produção em Rio Branco-AC. Pesquisa Agropecuária Brasileira, Brasília, v. 43, n. 8, p.1.003-1.010, 2008.

PEREIRA, L.V.; SILVA, S.O; ALVES, E.J.; SILVA, C.R.R. Avaliação de cultivares e híbridos de bananeira em Lavras-MG. Ciência e Agrotecnologia, Lavras, v. 27, n.1, p.17-25, 2003.

RAIJ, B. van; CANTARELLA, H.; QUAGGIO, J.A.; FURLANI, A.M.C. Recomendações de adubação e calagem para o Estado de São Paulo. 2. ed. rev. Campinas: IAC, 1997. 285p. (Boletim Técnico, 100). 
RAMOS, D.P.; LEONEL, S.; MISCHAN, M.M.; DAMATTO JÚNIOR, E.R. Avaliação de genótipos de bananeira em Botucatu-SP. Revista Brasileira de Fruticultura, Jaboticabal, v. 31, n. 4, p. 10921101, 2009.

RODRIGUES, M.G.V.; SOUTO, R.F.; SILVA, S.O. Avaliação de genótipos de bananeira sob irrigação. Revista Brasileira de Fruticultura, Jaboticabal, v. 28, n. 3, p. 444-448, 2006.

SAKAI, E.; LEPSCH, I.F. Levantamento pedológico detalhado da Estação Experimental de Pariquera-Açu. Campinas: Instituto Agronômico, 1984. 56p. (Boletim Técnico).

SANTOS, S.C.; CARNEIRO, L.C.; SILVEIRA NETO, A.M.; PANIAGO JÚNIOR, E.; PEIXOTO, C.N. Caracterização morfológica e avaliação de cultivares de bananeira resistentes à Sigatoka-negra (Mycosphaerella fijiensis Morelet) no Sudoeste Goiano. Revista Brasileira de Fruticultura, Jaboticabal, v. 28, n. 3 , p. $449-453,2006$.

SILVA, S.O.; ALVES, E.J. Melhoramento genético e novas cultivares de banana. Informe Agropecuário, Belo Horizonte, v. 20, n. 196, p. 91-96, 1999.

SILVA, S.O.; FLORES, J.C.O.; LIMA NETO, F.P. Avaliação de cultivares e híbridos de bananeira em quatro ciclos de produção. Pesquisa Agropecuária Brasileira, Brasília, v. 37, n. 11, p. 1.567-1.574, 2002.

SILVA, S.O.; GASPAROTTO, L.; MATOS, A.P.; CORDEIRO, Z.J.M.; FERREIRA, C.F.; RAMOS, M.M.; JESUS, O.N. Programa de melhoramento de bananeira no brasil - resultados recentes. Cruz das Almas: Embrapa Mandioca e Fruticultura, 2003a. 36p. (Documentos, 123).
SILVA, S.O.; MATOS, A.P.; ALVES, E.J. Melhoramento genético da bananeira. Pesquisa Agropecuária Brasileira, Brasília, v. 33, n. 5, p. 693-703, 1998. SILVA, S.O.; PASSOS, A.R.; DONATO, S.L.R.; SALOMÃO, L.C.C.; PEREIRA, L.V.; RODRIGUES, M.G.V.; LIMA NETO, F.P.; LIMA, M.B. Avaliação de genótipos de bananeira em diferentes ambientes. Ciência e Agrotecnologia, Lavras, v. 27, n. 4, p. 737-748, 2003b.

SILVA, S.O.; ROCHA, S.A.; ALVES, E.J.; CREDICO, M.; PASSOS, A.R. Caracterização morfológica e avaliação de cultivares e híbridos de bananeira. Revista Brasileira de Fruticultura, Jaboticabal, v 22, n. 2, p. 161-169, 2000

SILVA, S.O.; SHEPHERD, K.; ALVES, E.J.; DANTAS, J.L.L. Cultivares de banana. In: ALVES, E.J. A cultura da banana: aspectos técnicos, socioeconômicos e agroindustriais. Brasília: EMBRAPA-SPI, 1999. p. 85-105.

SIQUEIRA, D. L. Variabilidade e correlação de caracteres em clones de bananeira 'Prata'. 1984. 66 f. Dissertação (Mestrado em Fitotecnia) - Escola Superior de Agricultura de Lavras, Lavras, 1984.

SOTO-BALLESTERO, M. Bananos: cultivo y comercialización. 2. ed. San José: Litografia e Imprenta Lil, 1992. 674 p.

TEIXEIRA, L.A.J.; RUGGIERO, C.; NATALE, W. Manutenção de folhas ativas em bananeira 'Nanicão' por meio do manejo das adubações nitrogenada e potássica e da irrigação. Revista Brasileira de Fruticultura, Jaboticabal, v. 23, n. 3, p. 699-703, 2001

TEIXEIRA, L.A.J.; SPIRONELLO, A.; QUAGGIO, J.A.; FURLANI, P. Banana. In: RAIJ, B. van; CANTARELLA, H.; QUAGGIO, J.A.; FURLANI, A.M.C. (Ed.). Recomendações de adubação e calagem para o Estado de São Paulo. 2. ed. rev. Campinas: IAC, 1997. p. 131-132. (Boletim Técnico, 100) 